\title{
Innate talent in sport: from theoretical concept to complex reality - comment on Baker \& Wattie
}

\author{
Nikki Rommers ${ }^{1,2,3, *}$ \& Roland Rössler ${ }^{4,5}$ \\ 1 Department of Movement and Sports Sciences, Vrije Universiteit Brussel, Brussels, Belgium \\ 2 Department of Movement and Sports Sciences, Ghent University, Ghent, Belgium \\ 3 Research Foundation Flanders (FWO), Belgium \\ 4 Amsterdam Collaboration on Health and Safety in Sports, Amsterdam UMC, Vrije Universiteit, \\ Amsterdam, Department of Public and Occupational Health, Amsterdam Movement Sciences \\ 5 Department of Sport, Exercise, and Health, University of Basel, Basel, Switzerland \\ * Corresponding author: Pleinlaan 2, 1050 Brussels, Belgium \\ Tel: +32-2-6292755 \\ E-Mail: nikki.rommers@vub.be
}

\section{COMMENTARY}

\section{Article History:}

Submitted $17^{\text {th }}$ December 2018

Accepted 21 th December 2018

Published $7^{\text {th }}$ May 2019

\section{Handling Editor:}

Lisa Steidl-Müller

University of Innsbruck, Austria

Editor-in-Chief:

Martin Kopp

University of Innsbruck, Austria

\section{ABSTRACT}

Over the last 20 years, the concept of innate talent has been discussed in the literature, and different factors have been associated with talent in different sports. However, it should be noted that talent identification is sport-, or even position-specific, and no 'one size fits all' consensus can be established. Specific talent profiles should be developed, acknowledging the multidimensionality of talent by taking physical, physiological, cognitive, psychological, and motivational factors into account. These profiles should also be age-specific and adjusted for covariates such as maturational timing and training history. To make a step forward in talent identification, we should not only move ahead in identifying innate talent, but also acknowledge the multifaceted and dynamic nature of talent. Therefore, we recommend researchers and practitioners to start approaching talent as a multidimensional, complex system.

Keywords:

Talent identification - youth sport - complexity

Citation:

Rommers, N. \& Rössler, R. (2019): Innate talent in sport: from theoretical concept to complex reality - comment on Baker \& Wattie Current Issues in Sport Science, 4:106. doi: 10.15203/CISS_2019.106

This is a commentary on a CISS report article authored by Baker, J. \& Wattie, N. (2018). Innate talent in sport: Separating myth from reality. Current Issues in Sport Science, 3:006. doi: 10.15203/CISS_2018.006

\section{Introduction}

Baker and Wattie (2018) revisit in their review the concept of innate talent and relate it to the domain of sport. It is an important piece of work explaining the concept of innate talent and the potential relevance of this concept in the field of sport. It gives great insights in the current knowledge and practice within the field of talent identification in sport. The authors conclude that "any understanding of innate talent cannot be divorced from the necessity to understand the complete eco- logy of the developmental environment" (Baker \& Wattie, 2018). They emphasize the point that any talent identification factor needs to be measurable and needs to have an association with future performance in order to be of relevance to the field. Therefore, at this moment, it is very hard to determine whether identification of innate talent is possible, and whether it is of any relevance in a sports context. Our commentary will elaborate on the concept of talent in sport and the challenges of identifying talented youth athletes in the complex reality. 


\section{Talent identification in youth sport}

Talent identification starts with the difficult task to define 'talent'. Two distinct concepts are discussed in the field of sport science: giftedness and talent. Giftedness denotes the potential of children for becoming professional adult athletes (Gagné, 1995). Talent is a concept that is hard to define, but it generally refers to mastery of certain skills (Gagné, 1995). The term talent is often used when talking about gifted young athletes, who might have the potential to develop into future professionals and high performers (later in life). Throughout this commentary, we will use the term gifted to describe athletes who have the potential to make it into professional athletes, while the term 'talent' refers to the best performing athletes at that current moment.

The review of Baker and Wattie (2018) focusses on genetic predisposition with regards to talent. We are looking for the extremes in a continuum of a normally distributed variable in the population. To enable the development of gifted young athletes and provide them with all external support to lead them to the top, we want to identify these extreme values early enough, and label these individuals as gifted (Vaeyens, Lenoir, Williams, \& Philippaerts, 2008; Williams \& Reilly, 2000). However, when discussing genetic predisposition, we should not forget that an individual fulfilling the requirements for being 'gifted', will never succeed in a certain sport without starting to participate in the first place and then keep practicing (i.e. investing time) until reaching proficiency. Making it to the top normally requires a substantial amount of training and/or competition experience (Baker \& Young, 2014). This raises the question in which population we should look for our gifted athletes: should we look for certain characteristics in the general population of children (i.e. identification of extremes in the population), or can we assume that gifted athletes themselves will find their way to the sport in which they have the potential to excel (i.e. identification of the most gifted athletes in a specific sport)?

Current practice in talent identification focusses on athletes already involved in the sport. When searching for gifted athletes, the attention often moves to the currently best performing individuals. It is difficult to identify gifted athletes, as no clear standards are available. It is not easy to identify characteristics in young children that are important for top performance at adult level. Characteristics of gifted athletes are also very specific. Different sports (Pion et al., 2015), or even different playing positions within a team sport (Pion et al., 2018), require different abilities or at least a different combination of them. Therefore, a "one size fits all" consensus for talent identification in sports is not possible. Talent profiling should specifically target one sport, and one playing position. When such a specific profile is available, we should ask ourselves when to start identifying the potentially gifted athletes. In most sports, we see that it takes several years of committed training until the athlete could reach international level. In woman's gymnastics, where flexibility and strength-to-weight-ratio are key elements to performance, the optimum age for maximum performance is lower than for example in endurance sport where the cardiovascular system needs to be fully developed and trained which takes several years after puberty. Consequently, talents in gymnastics need to be identified earlier than in endurance sports.

Many characteristics sought after in the identification and detection of potentially talented athletes, such as motor performance, will only significantly develop during adolescence (Leyhr, Kelava, Raabe, \& Honer, 2018), and are biased by (relative) age, biological development, training level, and experience as well as training age at the moment of assessment (Leyhr et al., 2018; Lovell et al., 2015; Rommers et al., 2018; Vaeyens et al., 2006). Therefore, characteristics focused on in talent identification should be specific for a certain (biological) age in the first place. Furthermore, developmental variations, such as the maturational timing during adolescence, should be taken into account to make sure that young athletes are compared to athletes of the same physical and mental developmental stage (Meylan, Cronin, Oliver, \& Hughes, 2010).

The training experience is also a critical component to be considered when evaluating whether individuals can be considered as gifted athletes or talents (Helsen, Hodges, Winckel, \& Starkes, 2000). A margin in experience and training stimuli resulting in structural adaptations (e.g. muscles, cardio-vascular system) might make one individual more successful at a given point in time than another individual (Nottin et al., 2002), although the latter one might be more gifted. This training experience is often to be taken into account.

Apart from emphasizing relevant covariates such as maturational timing and training experience, the multidimensionality of the concept of 'giftedness' in general should be underpinned (Phillips, Davids, Renshaw, \& Portus, 2010). An example: elite cyclists show high VO2max values compared to the general population. Consequently, one might think of using VO2max tests to determine performance in road cyclists and to screen for talents. However, a higher VO2max value will not necessarily result in better race performance (Coyle et al., 1991). Therefore, a talent screening based on the $\mathrm{VO} 2 \mathrm{max}$ parameter (alone) might tell us who cannot make it to the world tour level (i.e. cyclists with values under a certain threshold) but not who will make it to the top. Many other factors are needed to eventually reach the top level. Apart from physical and physiological characteristics, also cognitive, psychological and motivational variables play a key role in the giftedness of an athlete. Not only the multidimensional characteristics at that specific moment, but also the expected learning curve, psychological readiness and motivation of the athlete and the people surrounding this athlete (Phillips et al., 2010).

So in general, we can conclude that talent identification is a much broader and more complex topic than innate talent. Even if we take all previously mentioned issues into account (looking in the general population, using multidimensional sport or position-specific talent profiles that vary with age, correct for covariates such as maturational timing, and the training history), we will still do not have the guarantee to identify the 
athletes that will make it to the top. This is not only because an athlete could drop out, due to some particular "inciting event" (e.g. an injury), or quit the sport in which he or she would have had the potential to excel, but often because of the complexity of talent identification.

\section{Future perspectives of talent identification}

Future research should move beyond the question of innate talent and the identification of individual factors, and focus on identifying the gifted athletes who have the potential to make it into future professionals. Hereby, the complex reality of giftedness should be acknowledged. Talent identification is a multifaceted, dynamic system looking at time varying factors that are interacting with each other. It is hard to draw a causal picture of potential pathways leading young gifted athletes towards expert proficiency in sports. There are many potential confounders and mediators in these pathways that should be taken into account. Therefore, in contrast with previous studies, we suggest to approach talent identification as a multidimensional, complex system. We might identify the elements composing the complex puzzle of what makes the gifted athlete. All these elements should be considered together and the causal pathways need to be studied if we want to identify young athletes with a high potential to reach expert level as adults.

\section{Funding}

The authors have no funding or support to report.

\section{Competing Interests}

The authors have declared that no competing interests exist.

\section{References}

Baker, J., \& Wattie, N. (2018). Innate talent in sport: Separating myth from reality. Current Issues in Sport Science (CISS).

Baker, J., \& Young, B. (2014). 20 years later: Deliberate practice and the development of expertise in sport. International Review of Sport and Exercise Psychology, 7(1), 135-157.

Coyle, E., Feltner, M., Kautz, S., Hamilton, M., Montain, S., Baylor, A., ... Petrek, G. (1991). Physiological and biomechanical factors associated with elite endurance cycling performance. Med Sci Sports Exerc, 23(1), 93-107.

Gagné, F. (1995). From giftedness to talent: A developmental model and its impact on the language of the field. Roeper Review, 18(2), 103-111.

Helsen, W., Hodges, N. J., Winckel, J. V., \& Starkes, J. L. (2000). The roles of talent, physical precocity and practice in the devel- opment of soccer expertise. J Sports Sci, 18(9), 727-736. doi: 10.1080/02640410050120104

Leyhr, D., Kelava, A., Raabe, J., \& Honer, O. (2018). Longitudinal motor performance development in early adolescence and its relationship to adult success: An 8-year prospective study of highly talented soccer players. PLoS One, 13(5), e0196324. doi: 10.1371/journal.pone.0196324

Lovell, R., Towlson, C., Parkin, G., Portas, M., Vaeyens, R., \& Cobley, S. (2015). Soccer Player Characteristics in English LowerLeague Development Programmes: The Relationships between Relative Age, Maturation, Anthropometry and Physical Fitness. PLoS One, 10(9), e0137238. doi: 10.1371/journal. pone.0137238

Meylan, C., Cronin, J., Oliver, J., \& Hughes, M. (2010). Talent Identification in Soccer: The Role of Maturity Status on Physical, Physiological and Technical Characteristics. International Journal of Sports Science \& Coaching, 5(4), 571-592. doi: 10.1260/1747-9541.5.4.571

Nottin, S., Vinet, A., Stecken, F., N'GUYEN, L. D., Ounissi, F., LECOQ, A. M., \& Obert, P. (2002). Central and peripheral cardiovascular adaptations to exercise in endurance-trained children. Acta physiologica scandinavica, 175(2), 85-92.

Phillips, E., Davids, K., Renshaw, I., \& Portus, M. (2010). Expert performance in sport and the dynamics of talent development. Sports Medicine, 40(4), 271-283.

Pion, J., Segers, V., Fransen, J., Debuyck, G., Deprez, D., Haerens, L., ... Lenoir, M. (2015). Generic anthropometric and performance characteristics among elite adolescent boys in nine different sports. Eur J Sport Sci, 15(5), 357-366. doi: 10.1080/17461391.2014.944875

Pion, J., Segers, V., Stautemas, J., Boone, J., Lenoir, M., \& Bourgois, J. (2018). Position-specific performance profiles, using predictive classification models in senior basketball. International Journal of Sports Science \& Coaching, 1747954118765054.

Rommers, N., Mostaert, M., Goossens, L., Vaeyens, R., Witvrouw, E., Lenoir, M., \& D'Hondt, E. (2018). Age and maturity related differences in motor coordination among male elite youth soccer players. I Sports Sci, 1-8. doi: 10.1080/02640414.2018.1488454

Vaeyens, R., Lenoir, M., Williams, A. M., \& Philippaerts, R. M. (2008). Talent identification and development programmes in sport : current models and future directions. Sports Med, 38(9), 703-714.

Vaeyens, R., Malina, R. M., Janssens, M., Van Renterghem, B., Bourgois, J., Vrijens, J., \& Philippaerts, R. M. (2006). A multidisciplinary selection model for youth soccer: the Ghent Youth Soccer Project. Br J Sports Med, 40(11), 928-934; discussion 934. doi: 10.1136/bjsm.2006.029652

Williams, A. M., \& Reilly, T. (2000). Talent identification and development in soccer. J Sports Sci, 18(9), 657-667. doi: $10.1080 / 02640410050120041$ 
